\title{
대규모 지진대비를 위한 학교방재교육 개선방안 The Development of Earthquake Disaster Prevention Education for Schools and its Application
}

\author{
최준호* · 최충익** \\ Choi, Junho*, and Choi, Choongik ${ }^{* *}$
}

\begin{abstract}
This article aims to explore disaster prevention education strategy for schools and attempts to make some implications for the applications of actual actions for disaster reduction in schools. The paper goes three stages to tackle disaster prevention education and disaster response. First, we reviewed the current status and underlying problems of disaster prevention in Korea and then conducted a case study with the Great Han-Shin Awaji Earthquake and the Great East Japan earthquake. Finally, we drew out some implications based on the improvements in terms of disaster prevention actions taken after Japanese earthquake. The results of this case study show that disaster prevention training should be based on the education programs involving students, not learning by rote.
\end{abstract}

Key words : Japan, Disaster Prevention Education, Great Han-Shin Awaji Earthquake, Great East Japan Earthquake

\section{요 지}

본 연구는 최근 대두되고 있는 우리나라의 대규모 지진대비를 위해 일본의 초중고 방재교육 과정과 특징을 살펴보고 정책적 시사점을 도출하고 있다. 이를 위해서 방재교육과 재난대응의 필요성을 세가지 관점에서 살펴보았으며, 한국의 방재교육의 현황과 문제점을 검토하고, 일본의 방재교육의 특징을 고베대지진과 동일본 대지진이후 개선된 사항 및 대책을 바탕으로 정책적 시사점을 도출하였다. 분석결과, 일본의 방재교육은 대지진 실제경험을 바탕으로 여러 차례에 걸쳐 실증성을 높였으며, 단순히 주입식 교육이 아니라 교육받는 학생들의 주체적인 행동을 유도하고 있는 것이 주요한 특징으로 나타났다.

핵심용어 : 일본, 방재교육, 고베대지진, 동일본대지진

\section{1. 서 론}

최근 경주, 포항 등 지역에서 규모 5.0 이상의 비교적 큰 지진이 발생하고 여진이 계속됨에 따라 지진에 대한 국민적 관심이 높아지고 있다. 특히 한반도 지진 관측이래 최대 규모라 할 수 있는 2016년 경주지진을 계기로 울산과 제주 등의 여러 지역에서 지진방재를 위한 대책을 수립하고 있다. 그도 그럴 것이 지진직후의 행정과 주민의 대처모습은 우리 가 지진에 대한 대비를 매우 소홀히 했다는 것을 보여주었고 현 상태로는 향후 대지진이 발생하는 만일의 경우 매우
막대한 피해를 입을 수 있기 때문이다.

대지진에 대한 효과적인 대책은 행정의 지원도 필요하지 만 그 한계가 있을 수 있기에 무엇보다 지역사회에서 지진피 해와 취약성에 대해 사전에 깊이 이해하고, 효율적인 대처방 안에 대해 여럿이 함께 공동으로 숙지하며 대비하는 것이다 (Pahl-Wostl, 2006; Chen et al., 2006; Bajek et al., 2008; Ikeda et al., 2008; Ikeda and Nagasaka, 2011; Na et al., 2009; Okada et al., 2013, Samaddar et al., 2014).

이를 뒷받침할 사례는 가까운 일본에서 있었던 두 차례의 대지진의 경험에서 찾아 볼 수 있다. 1995년 일본에서 발생한

*정회원, 강원대학교 행정학과 박사후 연구원(E-mail: smolts80@gmail.com)

Member, Post-DOC, Department of Public administration, Kangwon National University

**교신저자, 정회원, 강원대학교 행정학과 교수(Tel: +82-33-250-6813, Fax: +82-33-259-5606, E-mail: choich@kangwon.ac.kr)

Corresponding Author, Member, Professor, Department of Public administration, Kangwon National University 
고베(神戸)대지진1)에서는 구조된 사람 중 약 $85 \%$ 가 지역주 민에 의해 구출되었으며(CAO, 2003), 2011년 발생한 동일본 대지진2)에서는 쓰나미 리스크에 대해 다년간 방재교육을 실시해온 카마이시(釜石)지역의 초등학생 및 중학생들이 상황에 맞는 적절한 대피를 실행함으로써 $99.8 \%$ 가 생존하였 다3). 위의 사례에서 알 수 있듯이 대지진의 피해를 최소화하 기 위해서는 사전에 지역의 리스크를 이해하고, 지진 발생시 에는 상황에 맞는 적절한 대처법을 구사하며, 이를 위해 이웃과의 협력이 필요하다는 점이다. 이러한 방재능력의 함양 및 향상에 있어 방재교육은 가장 중요한 요소이며 (Shiwaku and Shaw, 2008) 그 학습의 장은 학교에서부터 출발한다고 할 수 있다. 특히, 지진의 피해에 대해 취약할 수 있는 초등학생, 중학생 그리고 지진대처에 나름의 협력적 역할을 할 수 있는 고등학생에 대한 방재교육을 위해서는 복합적인 요소가 고려되어야 한다. 즉, 초등학교, 중학교, 고등학교의 역량 수준에 따라 차별화된 방재교육의 실시가 필요하다.

그러나 최근 발생한 경주 및 포항에서의 지진에서 학교의 대응방안을 살펴보면 방재교육을 위한 학습의 장과는 거리 가 있었다. 지진발생시 대피가 우선되어야 함에도 자습이 진행된 사례가 있었고4), 지진이후 안전을 위해 학생을 귀가 를 시킨 교사에 대해 학교장이 질책한 사례5)도 있었다. 물론 학교의 대응이 신속히 이루어진 사례6)도 있으나 일부 에 불과하고, 지진 후에 나온 교육청에서 나온 대책이 일반적 이며 포괄적7)이어서 각기 학급에 적용하기에는 실효성이 미흡하다 점 등을 살펴보면 아직은 우리나라의 초중고교에 서의 지진방재교육이 체계성을 갖추었다고 볼 수는 없다.

이렇듯 적절한 지진방재교육에 대한 체계성이 제기되고 있는 가운데, 대규모 지진의 경험과 교훈을 바탕으로 한 일본의 지진방재교육의 체계화는 우리에게 시사하는 바가 크다.

구체적으로 살펴보면 일본에서는 고베대지진을 통해 지 진방재교육의 중요성을 재인식하였고(Yamori, 2010) 이를 위해 정부차원에서는 방재교육 추진방침을 세워 교육을 강화하였다. 동일본대지진 이후에는 ‘방재교육 - 방재관리

1) 일본 내각의 공식명칭은 효고현 남부지진 (兵庫県南部地震)이며, 지 진피해 지역이 오사카(大阪), 고베(神戸), 아와지(淡路)섬에 걸쳐 발생 하고 큰 지진피해를 초래하였다고 하여 한신 - 아와지 대진재(阪神淡 路大震㷋)라고도 한다.

2) 일본 내각의 공식명칭은 도호쿠지방 태평양연안 지진 (東北地方太本 洋沖地震)이며 동일본 지역에 걸쳐 발생하고 큰 지진피해를 초래하였 다고 하여 동일본대진재(東日本大震災) 라고도 한다.

3) Sankei News, March 10, 2014, '99.8 Percent Survival Rate, The Miracle of Kamaishi - The Effectiveness of Tsunamitendenko'. (in Japanese)

4) 인사이트, 2017년 11월 15일 보도, '지진 대피하려는 학생들에게 가만 히 있으라고 한...'.

5) 오마이뉴스, 2016년 9월 13일 보도, '경주 지진 후 학생 귀가시킨 교사 혼낸 교장'.

6) 뉴스원 2017년 11월 15 일 보도, '경주 교훈 정부 - 지자체·학교 대응 도 빨랐다(종합)'.

7) 경주포커스 2016년 9월 21일 보도, '지진공포 학교별 대응 제각각..'
등에 관한 지식인 회의'를 설립하여 고베대지진에서 세운 추진방침을 기반으로 학교 현장의 경험을 더욱 세밀히 파악 하고, 교훈을 전수하며, 방재교육 정책의 개정을 도모하였다 (MEXT, 2012a). 즉, 두 차례에 걸친 대지진을 겪으며 방재교 육의 목표를 설정하고 시대가 변화함에 따라 개선해야 하는 사항을 제시함으로써 지진방재교육이 체계화하였다.

또한 일본의 기본적인 학제(學制)는 우리나라와 같은 단 선형 6-3-3-4제이고, 방재교육을 학제에 맞춰 단계별로 실시 한다는 점에서 우리에게 시사하는 바가 크다고 할 수 있다.

본 연구의 목적은 지진방재교육의 필요성에 대한 논의를 바탕으로 우리나라에서 대책이 시급히 마련되어야 하는 초중고 지진방재교육의 발전방안을 찾고자 한다. 이를 위해 우리보다 앞서 체계화된 지진방재교육을 실시하고 있으며 두 번에 걸친 대지진의 경험을 통해 내용을 개정함으로써 실증성을 높인 일본의 지진방재교육의 사례를 종합적으로 고찰한다.

본 논문의 구성은 다음과 같다. 먼저 제 2 장에서는 지진방 재교육과 재난대응의 필요성을 논의한다. 제 3 장에서는 한국 지진방재교육의 현황과 문제점을 살펴보고 제 4 장에서는 일본의 방재교육을 고베대지진과 동일본대지진 이후로 나 누어 개선사항과 특징에 대해 분석한다. 마지막 제 5 장에서 는 우리에게 주는 시사점과 나아가야할 방향성을 도출하며 결론을 맺는다.

\section{2. 지진방재교육과 재난대응}

지진방재교육은 크게 세 가지로 분류할 수 있다. 첫째 학교에서 이루어지는 교육, 둘째 조직과 기관에서의 연수를 통한 교육, 셋째 일반인을 위한 사회교육이다. 이 세 가지 형태의 방재교육은 그 대상을 달리하므로 그 목적과 방법, 그리고 내용 또한 다르다고 할 수 있다. 또한 세 가지 모두 지진 대처방안 마련이라는 점에 있어 매우 중요하여 모두 적절한 형태로 실시되어야 한다.

그러나 방재교육의 가장 효율적인 실시효과를 얻기 위해 서는 조기교육이 중요한데 성인이 된 후실시하면 그 효과가 감소된다는 지적이 있다(Song et al., 2005). 즉, 재난관련 지식과 대처 방안은 어린 시절부터 익혀야 할 기초적 지식 및 능력인 것이다(Lee, 2006). 이러한 방재능력 함양을 위한 조기교육을 담당해야 하는 기관은 학교이며. 학교에서의 지진방재교육은 그 효과를 더욱 증대시키기 위하여 체계적 인 방안이 강구되어야 한다.

방재교육을 통한 재난대응은 다음과 같은 세가지 관점에 서 실시되어야 한다는 점이다.

첫째, 나의 생명을 지키기 위한 것이다. 그러나 대다수의 사람들은 위험에 이르기 전까지 이에 대해 무관심한 성향을 보인다(Son and Im, 2016). 이는 기본적인 행동요령이나 대처방법으로 많은 피해를 최소화할 수 있음에도 불구하고 
생명을 잃는 안타까운 사례로 이어지기도 한다. 이를 해결할 수 있는 수단으로써 방재교육은 효과적이라 할 수 있다. 즉, 방재활동의 제 1 주체인 자신을 보호하기 위한 교육이 실시되어야 한다.

둘째, 타인의 생명을 지키기 위한 것이다. 대지진은 저빈도 대규모 사건(low probability high consequence events)이다. 즉, 대지진은 발생할 가능성이 있지만 그렇다고 빈도가 크다 고 할 수는 없다. 또한 발생지역의 범위가 어느 곳이 될 지도 불확실하기 때문에 인간의 생애에서 대지진을 경험할 수 있는 확률이 높다고 말 할 수는 없다. 따라서 본인이 대지진으로부터 자신의 생명을 지키기 위한 지식과 능력을 습득함과 동시에, 타인의 생명을 보호하기 위한 지식과 능력 을 함양할 수 있는 교육이 실시되어야 한다(Yamori, 2011).

셋째, 다음 세대를 위한 것이다. 방재를 위한 정책이 수립 되어 이를 효율적으로 집행하기 위해서는 인재가 필요하다. 교육은 이러한 사회변화를 유도하고 직접적인 효과를 얻을 수 있는 유효한 수단이다(Lee, 2016a).

이상을 종합해보면 나와 타인의 생명을 재난으로부터 지키기 위해 방재교육을 받은 인재가 다음 세대의 육성을 위한 역할을 담당하는 것은 교육의 체계성과 지속성 측면에 서 매우 중요하며 이는 무엇보다 초중고 학교에서 실시되어 야 한다.

위험한 대상(hazard)으로부터 공간적 거리를 두는 방안 (대피)을 강구하는 것은 방재교육에서 중요한 역할을 차지한 다(Yamori, 2011). 그러나 방재교육은 단순히 일방적이고 보편적인 지식을 전달하는 전통적 교육방식에서 벗어나야 한다. 대지진에서의 상황은 매우 복잡하고 예측 불가능하며 우리가 놓여있는 여건이 각각 다른 만큼, 전문가에서 비전문 가로의 방재에 대한 '정답의 전달이라는 이분법적인 구도에 서 벗어나 그 자리, 그 지역에 맞는 '사회적으로 실현가능한 답(socially viable solution)'을 함께 학습하며 공유하는 것이 필요하다(Okada, 2006; Shiroshita, 2012).

\section{3. 한국의 방재교육 현황과 문제점}

\section{1 한국 방재교육 현황}

우리나라의 방재교육에 대한 관심은 1999년 씨랜드 청소 년 수련원 화재사고로 높아졌으나 이후에도 유사한 사고가 발생하였다8). 2014년 세월호 사고로 인해 다수의 학생들이 안타깝게 생명을 잃게 되면서 방재교육의 중요성이 다시금 대두되었다. 이를 계기로 교육부는 학교교육을 통해 생명존 중 - 안전의식을 높이고, 학교 시설과 활동시 안전을 강화하 는 것을 내용으로 하는 '생명존중안전사회 구현을 위한 교 육분야 안전 종합대책' 발표하였다. 교육부는 '세월호 침몰 사고, 마우나리조트 붕괴사고 등의 원인이 되어 온 생명경시

8) 2013년 태안 청소년 캠프 사고 등이 대표적 사례이다.
풍조를 바로잡고, 국가 혁신 수준의 대응책 마련하기 위함이 라고 추진배경을 설명하였다(MOE, 2014). 그리고 관계부처 합동으로 발표한 안전혁신 마스터플랜을 통해 초등학교 1-2학년 교육과정에 안전교과를 신설하고 이후 초등학교 3 학년부터 고등학교 3학년까지는 안전관련 단원을 신설하 도록 추진하였다. 또한 유아에서 고교단계까지 발달단계별 7대 안전교육 표준안을 개발하고 적용하도록 하였다(Korea Interagency, 2015).

그러나 이러한 학교 방재교육의 기본방침이 되는 정부의 대책들을 살펴보면 지진과 관련한 특별한 언급을 찾아볼 수가 없다. 다만, 교육부는 2015 개정 교육과정에 맞춰 방재 교육의 강화를 위해 관련 교과를 별도로 신설하였는데 여기 에 지진을 포함한 자연재난에 대한 관련사항이 명시되어있 다. 2016년 경주지진이 발생한 이후 발표된 ‘지진방재 종합 대책’에서 비로소 지진안전교육 확대 및 컨텐츠 마련을 하겠 다고 제시하몄으며 현재 추진중에 있다(Korea Interagency, 2016). 그리고 2017년부터는 각각의 법안에 의해 산발적으 로 시행하던 국민안전교육을 종합적이고 체계적으로 실시 하기 위해 ‘국민안전교육 진흥 기본법'을 시행하고 있다. 따라서 우리나라의 체계적인 지진방재교육은 현재 시작단 계에 있다고 할 수 있다(Table 1).

Table 1. The Policies for Disaster Prevention Education after Sewol Ferry Disaster

\begin{tabular}{|c|c|c|}
\hline Year & Agenda & Main Contents \\
\hline 2014 & $\begin{array}{l}\text { Announcement of } \\
\text { 'Comprehensive measures } \\
\text { for safety in education' }\end{array}$ & $\begin{array}{c}\text { Strengthening 'life } \\
\text { respect' \& 'safety } \\
\text { awareness' through school } \\
\text { education }\end{array}$ \\
\hline 2015 & $\begin{array}{l}\text { Announcement of 'The } \\
\text { master-plan for } \\
\text { safety-innovation' }\end{array}$ & $\begin{array}{l}\text { Guidelines for the } \\
\text { development of a new } \\
\text { textbook of 'Safety' }\end{array}$ \\
\hline 2015 & $\begin{array}{c}\text { Announcement of '2015 } \\
\text { Revised national } \\
\text { curriculum' }\end{array}$ & $\begin{array}{c}\text { Registering and organizing } \\
\text { the subject of 'Safe } \\
\text { Living' }\end{array}$ \\
\hline 2016 & $\begin{array}{c}\text { Announcement of } \\
\text { 'Comprehensive measures } \\
\text { for earthquake disaster } \\
\text { prevention' }\end{array}$ & $\begin{array}{c}\text { development of } \\
\text { earthquake disaster } \\
\text { prevention education \& } \\
\text { development of } \\
\text { educational contents }\end{array}$ \\
\hline 2017 & $\begin{array}{l}\text { Enforcement of } \\
\text { 'Framework act on the } \\
\text { promotion of safety } \\
\text { education for citizens' }\end{array}$ & $\begin{array}{l}\text { Implementation of safety } \\
\text { training and education }\end{array}$ \\
\hline
\end{tabular}

\section{2 문제점}

상술하였듯이 2015 개정 교육과정에 맞춰 방재교육의 강화를 위해 ‘안전한 생활9)'이라는 교과를 별도로 신설하였 는데, 여기에 지진과 같은 자연재난에 대한 관련사항 등이 
명시되어있다. 이 '안전한 생활'이라는 교과는 초등학교 1,2 학년에게 해당되는 것이며, 초등학교 3학년부터 고등학 교까지는 별도의 교과신설이 아닌 기존의 관련교과에 안전 단원을 신설하여 교육하도록 편성하고 있다. 교육부는 이를 저학년 단계부터 체계적으로 안전교육을 실시하려는 의도 라고 설명하였다(MOE, 2015).

그러나 이 2015 개정 교육과정은 4대 안전영역10)에 대한 교육에 폭넓게 중점을 두고 있으므로 -비록 지진에 대해 일부 기술되었다 하더라도- 지진방재교육으로서 충분하다 고 볼 수는 없다. 즉, 종전의 교육과정과 마찬가지로 방재교육 이 원론적인 내용으로 실시될 수 있다11). 또한 방재교육을 위한 담당인력의 조직적 문제나 연수기회 미흡 등의 문제는 종전 교육과정에서부터 꾸준히 지적된 사항들이다(NDMI, 2014).

방재교육은 이론적인 형식이 아니라 현실에 부합되어야 한다. 2016년 경주지진을 통해 이러한 문제점이 여실히 드러 났다. 경주지진이 발생한 2016년 9월 12 일 경북지역의 88 개 학교가 야간자율학습을 하고 있었는데 42 개 학교가 대피조 치를 취하지 않은 것으로 나타났으며, 대피를 하더라도 교사 의 임기응변에 따라 제각각이었다는 지적이 있다(National Assembly, 2016). 또한 경주지진 발생 4년전인 2012년 교육 부는 '학교현장 재난유형별 교육·훈련 매뉴얼'과 스마트폰 애플리케이션 '학교생활 안전 매뉴얼'을 제작하고 배포하였 으나 이것의 지진대응 행동요령을 살펴보면 '선생님 지시를 따라 안전한 장소로 대피하라', '가방-책 등으로 머리를 보호하라' 등의 일반적인 내용에 그치고 있다. 단순히 '선생 님의 지시에 따르라'는 지침은 지진방재에 대해 지식이 없거 나 사전에 학교주변의 대피장소를 인식하고 있지 않은 교사 에 경우에 혼란의 가중시킬 수 있다. 즉, 상술한 것처럼 일방적인 단순전달에 의한 방재교육인 것이다.

우리나라 교과과정과 교과서를 살펴보면 방재교육에 대 한 문제점을 더욱 확실하게 이해할 수 있다. 초중고의 자연재 해와 그 대책은 사회과 교육과정 중 지리영역에서 제시하고 있다(MOE, 2015b). 따라서 지진의 발생과 대응방안에 대해 서도 지리영역에서 이수되어야 있어야 하는데 미흡함이 드러난다.

초등학교 저학년(1,2학년)은 '안전한 생활'을 교과로 신설 하여 재난안전 영역중에서 지진을 간략히 다루고 있으나 중학년(3,4학년)에서는 관련내용이 설정되어 있지 않고, 더

9) 교사나 학생의 학습부담 증가를 고려하여 독립교과가 아닌 창의적 체험활동 시간을 이용해 수업을 진행한다(MOE, 2015).

10) 생활안전, 교통안전, 신변안전, 재난안전이며 지진은 이중 재난안전 영역에 속해있다.

11) 2014년 세월호 사고 이후 형식적인 방재교육을 실천적으로 개선하기 위해 방재교육 시간을 2016년 3월부터 초중고교에서 학년 당 51시간 이상 실시하도록 하였으나 지진 관련 내용은 51 시간 중 6 시간이상으 로 배정된 재난안전영역에 속해 있으며, 이 또한 각종사고 등과 같은 여러 재난유형과 함께 교육받도록 되어있어 지진방재에 대한 이수 시간은 부족하다고 할 수 있다.
구나 지진 및 해일은 제외되어 있다. 고학년(5,6학년)에서는 자연재해를 중심으로 대책 및 안전수칙을 실천하도록 하고 있으나, 중학교 과정에서는 기후에 관련된 자연재해를 다루 다 보니 홍수와 태풍, 가뭄과 황사에 대해서는 기술되어있으 나, 지형과 관련된 지진에 관한 내용이 미흡하다. 이는 고등학 교에 올라가서도 마찬가지 인데, 한국지리 과정에서 지진에 관한 내용은 제외되어있다(Shim, 2017). 즉, 지진을 자연재 해 중 하나로 다루고 있기는 하나 교육의 체계성과 지속성이 없으며, 교과과정에서 배우더라도 소극적으로 이해하는 수 준에 그치고 있다. 즉, 초중고 과정 동안 지속적으로 지진방재 교육을 실시할 수 있도록 배려하고 있지 않다는 것을 알 수 있다.

\section{4. 일본의 지진방재교육 특징 및 시사점}

우리나라의 방재교육은 교과가 신설되고 종전 교육과정 에 비해 이수시간 증가되었으나, 문제점도 남아있다는 것을 알 수 있었다. 강화된 방재교육은 2017년 3월부터 초등학교 1,2 학년부터 점진적으로 진행12)되고 있기 때문에 앞으로 개선의 여지는 충분하다고 할 수 있지만, 현 상태로는 내용적 측면에서도 부실하고, 수업방식도 방재지식의 일방적인 전 달이라는 패러다임에 갇혀 있으므로 향후 발생할 수 있는 대지진의 대비에 충분하다고 말할 수 없다.

이러한 문제의식을 가지고 본 장에서는 고베대지진과 동일본대지진의 경험과 교훈을 통해 실증적으로 개선된 일본의 지진방재교육의 추진방향과 특징에 대해 분석하고 시사점을 살펴본다.

\section{1 고베 대지진 이후의 개선 사항 및 특징}

1961년 재해대책기본법이 제정된 이후 일본의 자연재해 로 인한 연간 희생자 수가 급격히 감소하였다. 그러나 1995년 고베대지진은 재해대책기본법 제정(1961)의 계기가 된 1959 년 이세완태풍보다 더 많은 희생자를 기록13)하여 일본의 방재를 다시금 생각하는 계기가 되었다. 즉, 고베대지진에서 구조된 사람의 $80 \%$ 가 가족이나 주변 이웃에 의한 것이었듯 이 지역사회 곳곳에 미칠 수 없는 방재행정의 한계를 체감하 였고, 이는 지역사회 방재대책의 중요성으로 인식될 수 있었 기에 사회적으로도 방재교육의 방식에 근본적인 변화를 요구하게 되었다(Yamori, 2010).

고베 대지진 이후에 문부과학성을 중심으로 개선되어야 하는 방재교육 방식에 대해 논의되었다. 구조된 사람의 약

12) 2017년 3월: 초1 2학년 적용, 2018년 3월: 초1 4학년, 중1학년, 고1학 년 적용, 2019년 3월: 초1 6학년, 중1 2학년, 고1 2학년 적용, 2020 년 3월: 초1 고3학년 전학년 적용(출처: $\mathrm{MOE}, 2015$ )

13) 이세완 태풍의 희생자 수는 5,868 명, 고베대지진은 6,482 명인데, 고베 대지진 이전까지의 일본의 방재대책은 기본적으로 1959 년 발생한 이세완 태풍의 교훈을 통해 수립된 재해대책기본법을 바탕으로 하 고 있기 때문에 수해에 대한 방재능력향상에 특히 집중되어 있었다. 
$80 \%$ 이상이 가족이나 주변사람에 의해 구조되었다는 사실 이 알려지면서, 협동과 소셜 네트워크가 많이 주목받기 시작 하였으며 이러한 교훈을 바탕으로 효과적인 방재교육을 추진하기 위해서는 학교가 가정 및 지역사회와 함께 밀접한 협력을 도모해야 한다고 하였다(MEXT, 1996). 즉, 지진발생 시에는 방재의 기본인 자조(自助)를 바탕하면서, 이후 구조 를 받는 수동적인 교육에서 벗어나, 주변에 도움이 될 수 있는 능동적인 교육으로 바뀌고 있다(Yamori, 2009).

개선된 방재교육의 목표는 첫째 자신의 안전을 위한 정확 한 판단과 행동을 실시하며, 둘째 지역의 안전을 위해 도움이 될 수 있도록 하며, 셋째 지역의 자연환경 및 방재에 대한 기초적 - 기본적 사항을 평상시에 이해하는 것으로 하였다. 즉, 방재교육의 목표가 스스로의 판단과 행동을 통한 방재능 력 함양, 도움받는 입장에서 도움을 줄 수 있는 역할의 변화, 평상시의 지진 리스크에 대한 인식 및 이해증진으로 변화한 것이다.

Table 2에서 보듯 일본의 초·중·고 교육과정으로 교과 별 학습시간, 목표 등을 제시하여 교과서 검정기준의 근간이 되는 학습지도요령은 고베대지진 이후인 1998년 개정되었 는데 방재와 관련된 교육을 초중학교의 사회과 등에 포함시 켜 방재에 대한 지도를 강화하였으며, 지진 교훈을 통해 문제해결에 대한 주체적, 협동적, 창조적인 태도 함양을 목표로 하였다(Shim, 2015; Shim, 2017). 2001년부터는 '방 재교육 챌린지 플랜’ 프로그램을 신설하여 전국의 초중고를 대상으로 선진 방재교육을 실시하는 곳을 선정하고 정기적 으로 발표대회를 개최하여 시상을 하도록 하고 있다.

또한 2002년부터 종합적 학습시간을 신설하였는데 이는 특정 교과에 방재를 한정하는 것이 아니라 해저드(hazard) 요소와 사회적 배경, 재해에 대한 대응책 등 방재를 다양한 방면에 걸쳐 통섭적으로 교육할 수 있도록 한 것이다. 이렇게 고베대지진 이전에는 방재교육이 대피훈련에만 의존했던 '단발훈련형'에서 생명의 소중함을 알고, 이웃간의 친절을 베푸는 유대관계를 맺는 '지역사회 공동체적 생활'을 생각하 는 방재교육으로 크게 전환하였다(Sakurai, 2013).

구체적으로 살펴보면, 와카야마현(和歌山県)의 경우, 고 등학생이 가까운 노인복지시설의 고령자를 지원하는 훈련 교육을 실시하고 있으며, 효고현립(兵庫県立) 마이코(舞子) 고등학교의 경우는 지진발생시 할 수 있는 지진구조 지원활 동에 대해 생각하면서 지진대응에 대한 창의력을 키우는 수업을 실시하고 있다(Suwa, 2006). 또한 2018년도 '방재교 육 도전 플랜'의 선발학교인 가와구치시(川口)의 하토가야 시(鳩ヶ谷) 중학교에서는 시의 지도를 통해 학생이 지역의 고령자를 돕는 훈련과 방재교육을 실시하고 있다14). 이 교육 에서 주목할 점은 훈련교육에 앞서 시가 마련하는 방재리더 강습회를 통해 방재의식을 함양하고, 도덕수업을 통해 자신

14) Disaster Prevention Challenge, www.bosai-study.net
의 생명을 소중함을 깨닫기 위한 교육을 실시함으로써 자조 (自助)와 구조(救助)의 균형관계를 유지한다는 점이다.

Table 2. The Policies for Disaster Education of School after Great Han-Shin Awaji Earthquake in Japan

\begin{tabular}{c|c|c}
\hline Year & Agenda & Main Contents \\
\hline 1998 & $\begin{array}{c}\text { Revision of 'The } \\
\text { course of study' }\end{array}$ & $\begin{array}{c}\text { Strengthening } \\
\text { disaster prevention guidance } \\
\text { of the subject 'social } \\
\text { studies' in elementary and } \\
\text { middle school }\end{array}$ \\
\hline 2001 & $\begin{array}{c}\text { Implementation of } \\
\text { 'Disaster prevention } \\
\text { education challenge } \\
\text { plan' }\end{array}$ & $\begin{array}{c}\text { Advancement of national } \\
\text { disaster prevention } \\
\text { education for school \& } \\
\text { selection of excellent } \\
\text { schools in implementation }\end{array}$ \\
\hline & $\begin{array}{c}\text { New establishment of } \\
\text { 'Integrated Studies' }\end{array}$ & $\begin{array}{c}\text { Implementation of } \\
\text { interdisciplinary disaster } \\
\text { prevention education }\end{array}$ \\
\hline
\end{tabular}

\section{2 동일본 대지진 이후의 방재교육 방향성과 특징}

2011년 3월 발생한 동일본 대지진15)으로 인해 방재교육 은 새로운 전환점을 다시 맞이하게 되었다. 동일본대지진은 일본 지진관측사상 가장 큰 대지진이었으며, 태평양 연안 지역에 큰 쓰나미가 발생하여 내륙의 광범위한 지역에 큰 피해를 가져왔다.

이러한 상황에서 이와테현(岩手県) 카마이시시(釜石市) 의 초중학교 학생 2,926명 중 $99.8 \%$ 가 다년간에 걸친 방재교 육과 훈련을 통해 쓰나미 발생당시 적절한 대피를 이행함 (implementation)으로써 생존하였다16).

카마이시의 방재교육은 '쓰나미 예측범위를 믿지 말 것', '먼저 솔선수범하여 대피 할 것', '최선을 다해 대피할 것'으 로 요약된다(Katada, 2016). 즉, 기존에 해저드맵(hazard map)에 예측된 재난의 범위에 자신의 판단을 구속하지 않고, 재난 발생시 먼저 피난을 함으로써 주변의 동조를 이끌어 내며, 자신이 할 수 있는 최대한의 대피행동을 이행해야 한다는 것이다. 이는 주체적인 판단과 행동을 강조한 것이라 할 수 있다. 방재에 대한 기술과 지식의 일방적인 전달이라는 전통적 방재교육관에서 벗어난 것이라 할 수 있다(Shirshita, 2012; Miyagi, 2014; Nakamura 2017). 또한 일본의 방재교육 은 위의 교훈을 바탕으로 발달단계에 따라 다르게 실시하도 록 하고 있다. 초등학교 저학년까지는 '인근 어른의 지시에 따라 적절하게 행동한다’고 하고 있으며, 중학년에서부터는 '스스로 안전한 행동이 가능하도록'하며, 고학년에서는 '다 른 사람의 안전에도 배려'하는 자세를 강조하고 있다. 중학교 에서는 재난이후의 자원봉사활동의 중요성을 언급하고 있

15) 직간접 사망자는 19,418 명 (MIC, 2016)

16) 일본에서는 '카마이시(釜石)의 기적'으로 통칭되고 있다. 
으며, 고등학교에서는 지역사회의 안전에 기여하는 태도를 함양하고 스스로의 역할을 자각하며, 재난 시 자원봉사활동 에 적극 참여해야 한다고 강조하고 있다(MEXT, 2012b). 이렇듯 일본의 방재교육은 동일본 대지진 이후에도 대피 훈련에 의존하는 방식이 아닌 삶의 태도와 방향성을 생각하 는 교육으로 전환되고 있다(Lee, 2016b).

\section{5. 결 론}

지금까지 지진에 대한 관심이 높아지고 있는 우리나라에 서 학교 지진방재교육에 대한 중요성을 살펴보고 현행 문제 점을 지적한 후, 고배대지진과 동일본대지진 이후 새롭게 전환하고 있는 일본 지진방재교육의 개선사항과 특징을 살펴보았다.

일본의 지진방재교육의 특징을 요약하자면, 대지진을 실 제 겪은 경험을 바탕으로 여러 차례에 걸쳐 실증성을 높였으 며, 일방적인 방재지식의 정보전달이 아니라 상호 이해를 통해 지진 발생시 주체적으로 판단을 할 수 있도록 유도하고 스스로 재난피해에서 벗어나기 위한 해결책을 찾는 방안을 강구한다는 점이다. 이때의 해결책은 자신뿐만 아니라 주변 이웃, 지역사회에까지 범위를 확대함으로써 대지진시 협력 의 중요성과 지역사회 일원으로서 삶의 태도까지 생각하는 체계화된 교육으로 발전하고 있다. 즉, '대피'로 대표되는 단순한 재난으로부터의 회피(avoidance)능력을 강화하기 위 한 교육이 아니라 적극적인 방재태도를 형성하기 위한 교육 이라 할 수 있다.

앞으로의 방재교육은 전문가가 비전문가에게 방재지식 을 일방적으로 전달방식에서 벗어나야 하며, 위협적인 정보 전달을 통해 방재의식을 높이려는 교육방식에서도 벗어나 야 한다. 중요한 것은 향후 발생가능한 재난으로 인해 겪을 수 있는 문제에 대해 판단할 수 있는 주체성을 불러일으키면 서 재난대응방안에 대한 해결의 오너쉽(ownership)을 부여 하는 것이 중요하다.

최근 우리나라에서 잇달아 발생한 작지 않은 규모의 지진 으로 인해 경주, 포항 등의 지역에서 피해가 발생하였으며 그 대처도 미숙하였다. 후속조치로 '지진방재 종합대책' 등이 발표되고 학교 방재교육에 대한 개선이 진행되고 있는 상황이기에 우리나라의 지진방재교육은 아직 초기단계라고 할 수 있다.

일본 내에서도 일부 학자들이 자국의 방재교육에 대한 한계점을 지속적으로 지적하고 있는데, 이는 방재교육이론 과 실습에 대한 반증가능성으로 작용하여 개선의 여지를 준다는 점에서 매우 긍정적인 현상이라 볼 수 있다.

일본의 지진방재교육은 실제 대지진의 경험을 바탕으로 우리보다 앞서 교육의 방향성을 잡고 충실히 개선하였다는 점에서 우리나라에서 앞으로 발생할지 모르는 대지진에 대비한 선험적 사례로써 매우 의의가 있다고 할 수 있다.
우리나라도 일본의 사례를 참고하여 더욱 유용한 지진방재 교육 방안을 마련해야 할 것이다.

\section{감사의 글}

본 연구는 2017년도 강원대학교 대학회계 학술연구조성 비로 수행되었으며(No. 520170342), 2017년 정부(교육부) 의 재원으로 한국연구재단의 지원을 받아 수행되었습니다 (NRF-2017S1A3A2066149).

\section{Reference}

Bajek, R., Matsuda, Y., and Okada, N. (2008) Japan's Jishu-bosai-soshiki Community Activities: Analysis of its Role in Participatory Community Disaster Risk Management. Natural Hazards, Vol. 44, No. 2, pp. 281-292.

CAO (2003) The 2003 Disaster Prevention White Paper. (in Japanese)

Chen, L.C., Liu, Y.C., and Chan, K.C. (2006) Integrated Community Based Disaster Management Program in Taiwan: A Case Study of Shang-An Village. Natural Hazards, Vol. 37, pp. 209-223.

doi:10.1007/s11069-005-4669-5

Ikeda, S., and Nagasaka, T. (2011) An Emergent Framework of Disaster Risk Governance towards Innovating Coping Capability for Reducing Disaster Risks in Local Communities. Int. J. Disaster Risk Sci., Vol 2, No. 2, pp. 1-9. doi:10.1007/s13753-011-0006-7.

Ikeda, S., Sato, T., and Fukuzono, T. (2008) Towards an Integrated Management Framework for Emerging Disaster Risks in Japan. Natural Hazards, Vol. 44, No. 2, pp. 267-280. doi:10.1007/s11069-007-9124-3

Katada, T., and Kanai, M. (2016) The School Education to Improve the Disaster Response Capacity: A Case of "Kamaishi Miracle". Journal of Disaster Research, Vol. 11, No. 5, pp. 845-856.

Korea Interagency (2015) The Master-plan for Safetyinnovation.

Korea Interagency (2016) Comprehensive Measures for Earthquake Disaster Prevention.

Lee, H.D. (2006) e-Learning System for Disaster Prevention \& Emergency Management Training Program in Japan. Proceedings of 2006 Autumn Conference, The Korea Contents Association, Vol. 4, No. 2, pp. 372-376.

Lee, J.H. (2016a) A Study on the Current Situation of Safety 
Education in Elementary Schools and Improvement of Teaching Safety in Social Studies Education. The Journal of Korea Elementary Education, Vol. 27, No. 2, pp. 259-278.

Lee, J.H. (2016b) A Study on the Principle in Organizing the Contents of Natural Disaster and Disaster Preventing Education in Elementary Social Studies in Japan. Korean Journal of the Japan Education, Vol. 20, No. 2, pp. 21-44.

MEXT (1996) Second Report of Establishing Disaster Prevention System at School. (in Japanese)

MEXT (2008) National Curriculum of Elementary School. (in Japanese)

MEXT (2012a) Final Report of Intelligent Conference about Disaster Education and Disaster Management after the Great East Japan Earthquake. (in Japanese)

MEXT (2012b) The Plan about the Promotion of the School Security. (in Japanese)

MIC (2016) Great East Japan earthquake Damage State (May 1, 2016). (in Japanese)

Miyagi, T. (2014) GIS Based Communicative Hazard Mitigation Mapping and the Application to Geographical Education. Trends in the Sciences, Vol. 19, No. 9, pp. 48-52. (in Japanese)

MOE (2014) Comprehensive Measures for Safety in Education. MOE (2015a) 2015 Revised National Curriculum.

MOE (2015b) 2015 Revised Social Studies Curriculum.

Na, J.I., Okada, N., and Fang, L. (2009) A Collaborative Action Development Approach to Improving Community Disaster Reduction Using the Yonmenkaigi System. Journal of Natural Disaster Science, Vol. 30, pp. 57-69.

Nakamura, M. (2017) The Change in Disaster-related Consciousness of Junior Highschool Students after the Great East Japan Earthquake and Findings on Designing Sustainable Learning Environments for Disaster Prevention Programs. Journal of Japan Society for Natural Disaster Science, Vol. 36, No. 1, pp. 87 -107. (in Japanese)

National Assembly of the Republic of Korea (2016) 2016 National Assembly Data.

NDMI (2014) Development of Disaster Safety Education Contents for Elementary Students. NDMI Report.

Okada, N. (2006) Perspective on integrated disaster risk management. Introduction to Integrated Disaster Risk Management, Edited by Hagihara, Y., Okada, N., and Tatano, H., Kyoto University Academic Press, pp.5-9. (in Japanese)

Okada, N., Na, J.I., Fang, L., and Teratani A. (2013) The Yonmenkaigi System Method: An Implementation Oriented Group Decision Support Approach. Group Decis. Negot., Vol. 22, No. 1, pp. 53-67.

Pahl-Wostl, C. (2006) The Importance of Social Learning in Restoring the Multifunctionality of Rivers and Floodplains. Ecol. Soc., Vol. 11, No. 1, Article No. 10, Retrieved from http://www.ecologyandsociety.org/vol11/iss1/art10/ Sakurai, A. (2013) A Preliminary Study on Disaster Education in Japan: From a Perspective of Disaster Risk Management. Journal of International Cooperation Studies, Vol. 20, No. 2-3, pp. 147-169. (in Japanese) Samaddar, S., Choi, J.H., Misra, B.A., and Tatano, H. (2015) Insights on Social Learning and Collaborative Action Plan Development for Disaster Risk Reduction: Practicing Yonmenkaigi System Method (YSM) in Flood-prone Mumbai. Natural hazards, Vol. 75, No. 2, pp. 1531-1554. doi:10.1007/s11069-014-1380-4 Shim, J.B. (2017) Exploring the Direction of the Disaster Prevention Education to Prepare Natural Disasters. The Journal of the Korean Association of Geographic and Environmental Education, Vol. 25, No. 4, pp. 89-101.

Shim, M.S. (2015) A Study on Safety and Disaster Preventing Education in Elementary Social Studies: Implications of the Elementary Social Studies of Japan. Social Studies Education, Vol. 54, No. 3, pp. 53-67.

Shiroshita, H. (2012) Disaster Education after The Great East Japan Earthquake. Safety Science Review 2011, Vol. 2, pp. 44-45. (in Japanese)

Shiwaku, K., and Shaw, R. (2008) Proactive Co-learning: A New Paradigm in Disaster Education. Disaster Prevention and Management: An International Journal, Vol. 17, No. 2, pp. 183-198.

Son, O.K., and Im, S.M. (2016) Effect of Safety and Science Integrated Educational Program on Safety Consciousness of Middle School Students with Special Educational Needs. The Journal of Special Education: Theory and Practice, Vol. 17, No. 1, pp. 143-166.

Song, M.K., Lee, J.E., Moon, S.Y., Yang, S.J., and Kim, S.J. (2005) Contents Analysis of Textbook Related to Safety Education in Elementary School. Journal of Korean Academy of Community Health Nursing, Vol. 16, No. 2, pp. 205-220.

Suwa, S. (2006) New Disaster Prevention Education by Using 
a Lesson Learned from Han-Shin Awaji Earthquake Disaster. Journal of Japan Society for Natural Disaster Science, Vol. 24, No. 4, pp. 356-363. (in Japanese)

Yamori, K. (2009) Action Research on Disaster Reduction Education: Building a "Community of Practice" through a Gaming Approach. Journal of Natural Disaster Science, Vol. 30, No. 2, pp. 83-96.

Yamori, K. (2010) Disaster Education and its Future Perspectives in Japan Following the Great HanshinAwaji Earthquake. Journal of Japan Society for
Natural Disaster Science, Vol. 29, No. 3, pp. 291-302. Yamori, K. (2011) The Roles and Tasks of Implementation Science on Disaster Prevention and Reduction Knowledge and Technology: From Efficient Application to Collaborative Generation. Journal of Integrated Disaster Risk Management, Vol. 1, No. 1, pp. 48-58.

\begin{tabular}{|l|l}
\hline Received & April 18, 2018 \\
\hline Revised & April 19, 2018 \\
\hline Accepted & April 27, 2018
\end{tabular}

